\title{
Prediction of bending rigidity for laminated weft knitted fabric with adhesive interlining
}

\author{
KyoungOk Kim ${ }^{1}$, Shigeru Inui ${ }^{2}$, Masayuki Takatera ${ }^{2 *}$ \\ Department of Bioscience and Textile Technology, Interdisciplinary Division of Science and Technology, Shinshu \\ University, Ueda, Japan \\ Faculty of Textile Science and Technology, Shinshu University, Ueda, Japan \\ *takatera@shinshu-u.ac.jp
}

\begin{abstract}
The purpose of this study is to predict bending rigidity of laminated weft knitted fabric using three prediction methods and to determine their suitability for predicting. The methods are as follows: Method 1: the laminate theory using bending rigidities and thicknesses of components, Method 2: an equation derived from the laminate theory taken into account the tensile and in-plane compressive moduli of components, Method 3: an equation in consideration of the position of the neutral axis in bending on a face fabric. Six weft knitted fabrics and ten adhesive interlinings, sixty laminated composites with those combinations were used. Tensile properties and bending rigidities, thicknesses of samples were measured. The other necessary parameters for the prediction were obtained by additional experiments and calculation. It was found that the results by Method 3 showed the closest agreements with experimental ones. It is due to the relative positions of the neutral axes for all knitted fabric samples are not in the centroid. It became clear that the position must be taken into account for calculating bending rigidities of laminated knitted fabric with adhesive interlining.
\end{abstract}

\section{Introduction}

Knitted fabrics have been used for various garments such as sweaters, underwear, hosiery, and baby blankets because of their soft, stretchy and drapery properties. A trend toward a casual lifestyle reflected in knitted garments. As this trend also affects the formal style, people would like to wear softer and stretchier garments even in the case of wearing suits. Thus, suits and other outwear made of knitted fabrics have appeared on the market.

For manufacturing garments, mechanical properties of fabrics are controlled using subsidiary materials due to the insufficient stiffness of a face fabric. An adhesive interlining using a thermoplastic resin is taken as a representative example. Adhesive interlinings are used for knitted fabrics as well as woven fabrics to give suitable appearance and stability to garments.

In the previous studies [1,2 and 3], the prediction of bending rigidity for laminated fabric with woven fabric and adhesive interlining were investigated using three prediction methods as shown below. It became clear that changes of mechanical properties of components by pressing process are necessary to be considered in laminate theory [1]. It was also found that bending rigidities of laminated fabrics can be predicted using tensile and in-plane compressive moduli of components [2]. For more precise prediction of bending rigidities, the placements of neutral axes were effective to be taken into account for some fabrics [3]. From these results, it was possible to predict bending rigidity of laminated fabric with woven fabric and adhesive interlining. However these predictions were mainly carried out with woven fabrics for face fabrics. The tensile and in-plane compressive properties of knitted fabric have not been investigated yet. Thus, it is uncertain if these methods will be suitable for knitted fabric because of its different structures and mechanical properties with woven fabric.

Viki L. Gibson et al. [4] investigated mechanical properties of a wide range of commercially-produced outerwear fabrics, woven fabrics, double-knits, and warp-knits in terms of the elastic and frictional resistance to bending and shear deformations. They reported the different bending properties depending on different fabric structures. D. Alimaa et al. [5] also investigated bending properties of a series of plain and rib weft knitted structures, and carried out theoretical analyses on the effects of yarn bending properties and fabric structure on the bending rigidity. However, those studies did not investigate laminated knitted fabrics.

Some studies were carried out to predict the bending rigidity of laminated knitted fabrics. Dawes V H et al. [6] investigated the prediction of bending rigidity for composite with one knitted fabric taken into account the tensile and in-plane compressive moduli. However, it showed unsatisfactory prediction results with large prediction errors. Shishoo et al. [7] also introduced regression equations for the bending rigidity of laminated knitted fabrics. They also tested one knitted fabric sample and did not consider the mechanical properties of knitted fabrics. Thus, more precise predicting the bending rigidity of laminated knitted fabric is necessary.

Therefore, our aim in this study is to investigate the validity of these prediction methods of bending rigidity for laminated knitted fabrics, and to determine the most suitable ones. By investigating the prediction method for knitted fabrics, selecting the suitable adhesive interlining for knitted fabric will be possible without testing laminating fabrics on 
every case.

\section{Prediction methods}

\section{Method 1}

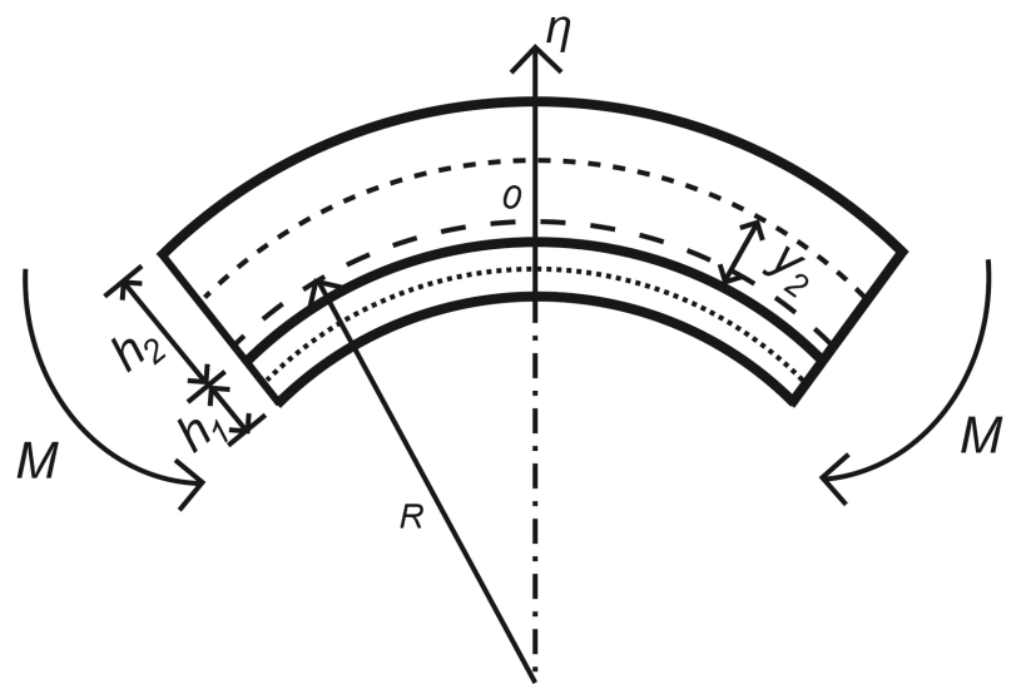

Figure 1 Structure of laminated fabric.

The laminate theory for elastic continua can be basically used to predict the bending rigidity of laminated fabric [1]. The equation is given by

$$
B_{12}=3 B_{1} B_{2} \frac{\left(h_{1}+h_{2}\right)^{2}}{\left(B_{1} h_{2}^{2}+B_{2} h_{1}^{2}\right)}+B_{1}+B_{2}
$$

where $h_{1}$ and $h_{2}$ are the thicknesses of adhesive interlining and face fabric as shown in Figure 1. $B_{1}$ and $B_{2}$ are the bending rigidities of adhesive interlining and face fabric. $B_{12}$ is the bending rigidity of laminated fabric with adhesive interlining. The method used Equation (1) is denoted by Method 1.

\section{Method 2}

Because a fabric is not elastic continuum, the tensile and in-plane compressive moduli, $E_{t}$ and $E_{c}$ may be different from the elastic modulus in bending, $E_{b}$. As assuming that $E_{b}, E_{t}$ and $E_{c}$ of both fabrics are independent and the neutral axes in bending are in the centroid of each fabric, Equation (1) can be expressed with in-plane compressive and tensile moduli as follows [2].

$$
B_{12}=\frac{T_{1} T_{2}}{T_{1}+T_{2}}\left(\frac{h_{1}+h_{2}}{2}\right)^{2}+B_{1}+B_{2}
$$

where $T_{1}$ and $T_{2}$ are apparent in-plane compressive modulus and apparent tensile modulus respectively and were assumed as constants. The apparent tensile modulus, $T_{2}$ can be obtained by a tensile test. To obtain the apparent in-plane compressive modulus, $T_{1}$, Equation (3) was proposed.

$$
T_{1}=\frac{-T_{2}\left\{B_{12}-\left(B_{1}+B_{2}\right)\right\}}{B_{12}-\left(B_{1}+B_{2}\right)-T_{2}\left(\frac{h_{1}+h_{2}}{2}\right)^{2}}
$$

$T_{1}$ can be obtained by a bending test of a combination of an adhesive interlining and a specific fabric, then, we can predict the bending rigidity of laminates with the interlining and other fabrics by Equations (2). The method used Equations (2) and is denoted by Method 2.

\section{Method 3}

The relative position of the neutral axis in bending, $Y_{2}$ for a face fabric was taken into account in predicting the bending rigidity of laminated fabric for more precisely [3]. The prediction equation in consideration of $Y_{2}$ is given by

$$
B_{12}=\frac{T_{2} T_{1}\left(h_{1}+2 Y_{2} h_{2}\right)\left(h_{2}+h_{1}\right)}{4\left(T_{1}+T_{2}\right)}+B_{1}+B_{2}
$$

Equation (5) can be used to obtain $Y_{2}$.

$$
Y_{2}=\frac{2\left(B_{12}-B_{1}-B_{2}\right)}{h_{2}\left(h_{1}+h_{2}\right)}\left(\frac{1}{T_{2}}+\frac{1}{T_{1}}\right)-\frac{h_{1}}{2 h_{2}}
$$


$Y_{2}$ can be obtained by a bending test of a combination of a fabric and an adhesive interlining, then, we can predict the bending rigidity of laminates with fabric and other interlinings. The method used Equations (4) is denoted by Method 3.

\section{Experimental}

Experiments were carried out to confirm the validity of the three prediction methods for the bending rigidity of laminated knitted fabrics. In the usage of adhesive interlinings, an adhesive interlining was used on the inside of clothing and the face fabric was on the outside of the arc of bending as shown in Figure 1. Weft knitted fabrics having different structures, adhesive interlinings and laminated fabrics with those combinations were prepared as experimental samples.

\section{Obtaining parameters for prediction methods}

Bending rigidities of all samples were measured on warp and weft, on wale and course direction respectively using a KES-FB2 pure bending tester [8]. The thickness of each sample was measured using a KES-FB3 compression tester at $49 \mathrm{~Pa}$ load in the thickness direction. The load at 0 to about $2.5 \%$ of elongation from the load-elongation curve by KES-FB1 tensile tester, on warp and weft, on wale and course direction respectively, was used to calculate the $T_{2}$ for each face fabric. $T_{1}$ can be obtained when the neutral axes in bending of components are assumed to be in the centroids of both components. However, it is uncertain that the neutral axes of knitted fabric samples pass through those centroids of the cross section. The centroids are the centers of each cross section. Thus, we carried out the experiments in the combination of specific face fabrics (N1 and N2) and interlining, which neutral axes in bending can be assumed to lie in the centroid [2]. With the obtained values, $T_{1}$ was calculated using Equation (3). Then, $Y_{2}$ of face fabrics were calculated by Equation (5).

Every test was carried out under standardized conditions $\left(20 \pm 1^{\circ} \mathrm{C}\right.$ and $65 \pm 5 \%$ relative humidity). All samples were preconditioned under these standardized conditions for 24 hours. Every test was conducted on five samples and the averages were used.

The bending rigidities of other laminated fabrics bonded with the face fabrics and different interlinings were predicted using Method 1, 2 and 3. Those results were compared with the experimental data.

\section{Experimental samples}

The sample specifications are shown in tables 1, 2 and 3. Six weft knitted fabrics were used for face fabrics. Two twill fabrics (N1 and N2 which $Y_{2}$ can be assumed to lie in the centroid [2]) were used for face fabrics to obtain $T_{1}$ of adhesive interlinings. Ten adhesive interlinings, which are usually used for knitted fabrics in the market, were also used. Sixty combinations of laminated fabrics were constructed and examined. They were polyester plain fabrics and the adhesive agent was polyamide of dot printing type. Laminating interlining to face fabric was done automatically using a press machine (Kobe Denki Kogyosyo, BP-V4812D). Adhesive interlining was put on face fabric and both were inserted in the press machine. The press machine was flat type press machine which had one heating side and another none heating side. The interlining side was heated. After pressing both fabrics, those were bonded. The bonding conditions were $150^{\circ} \mathrm{C}$, under $29.4 \mathrm{kPa}$ load and 10 s pressing time.

\section{Pressed samples}

The mechanical properties of woven fabrics and adhesive interlinings were changed after pressing procedure for laminating. This must be considered when predicting the bending rigidity of laminated fabrics [1]. However, the changes in bending rigidities and thicknesses of knitted fabric are unclear. Thus, the changes in mechanical properties of knitted fabric by pressing were also investigated. To investigate it, the samples which were pressed alone under the same press conditions of laminating were prepared. Those mechanical properties were measured and compared to the samples before pressing. The method is as follows: Face fabric samples were pressed using the press machine under the same conditions of bonding interlining. For adhesive interlinings, polytetrafluoroethylene (PTFE) film (NITTO, No.900, $0.05 \times 300 \mathrm{~mm}$ ) was prepared. Adhesive interlinings were bonded to PTFE films and then PTFE films were removed from adhesive interlining. The samples pressed alone were referred to as 'pressed samples'. Face fabric and adhesive interlining pressed alone were referred to as 'pressed face fabric' and 'pressed adhesive interlining'. 
Table 1 Specifications of knitted fabrics

\begin{tabular}{|c|c|c|c|c|c|c|c|c|}
\hline $\begin{array}{l}\text { Sample } \\
\text { name }\end{array}$ & $\begin{array}{r}\text { Yarn co } \\
\text { (warp }\end{array}$ & $\begin{array}{l}\text { nt (tex) } \\
\text { weft) }\end{array}$ & Structure & $\begin{array}{c}\text { Stitch } \\
\text { density }(/ \mathrm{cm}) \\
\text { (WalexCourse) }\end{array}$ & Material & $\begin{array}{l}\text { Pressed face } \\
\text { fabric name }\end{array}$ & $\begin{array}{c}\text { Bending rigidity } \\
\text { of pressed face } \\
\text { fabric }\left(\mathrm{cN} \cdot \mathrm{cm}^{2} / \mathrm{cm}\right) \\
\text { (WalexCourse) } \\
\text { (Standard deviation) }\end{array}$ & $\begin{array}{c}\text { Thickness of } \\
\text { pressed face } \\
\text { fabric } \\
\text { (cm) } \\
\text { (Standard } \\
\text { deviation) }\end{array}$ \\
\hline N1 & $\begin{array}{c}16.5 \\
\text { tex } \times 2 ; \\
\text { R33tex }\end{array}$ & $\begin{array}{c}16.5 \\
\text { tex } \times 2 ; \\
\text { R33tex }\end{array}$ & $\begin{array}{c}\text { twill } \\
\text { (woven) }\end{array}$ & $\begin{array}{c}28 \times 22 \\
(\text { warp } \times \text { weft })\end{array}$ & Wool $100 \%$ & P-N1 & $\begin{array}{l}0.135 \times 0.076 \\
(\text { warp } \times \text { weft }) \\
(0.002 \times 0.001)\end{array}$ & $\begin{array}{c}0.052 \\
(0.001)\end{array}$ \\
\hline $\mathbf{N} 2$ & $\begin{array}{l}14 \text { tex } \times 2 ; \\
\text { R28tex }\end{array}$ & $\begin{array}{l}14 \text { tex } \times 2 ; \\
\text { R28tex }\end{array}$ & $\begin{array}{c}\text { twill } \\
\text { (woven) }\end{array}$ & $\begin{array}{c}29 \times 24 \\
(\text { warp } \times \text { weft })\end{array}$ & Wool $100 \%$ & $\mathrm{P}-\mathrm{N} 2$ & $\begin{array}{l}0.057 \times 0.037 \\
(\text { warp } \times \text { weft }) \\
(0.001 \times 0.002) \\
\end{array}$ & $\begin{array}{c}0.050 \\
(0.002)\end{array}$ \\
\hline KN1 & \multicolumn{2}{|c|}{30} & plain & $14 \times 14$ & cotton $100 \%$ & P-KN1 & $\begin{array}{c}0.071 \times 0.011 \\
(0.003 \times 0.001)\end{array}$ & $\begin{array}{c}0.064 \\
(0.001)\end{array}$ \\
\hline KN2 & \multicolumn{2}{|c|}{$22 / 22$} & milano rib & $14 \times 12$ & poly $85 \% /$ cotton $15 \%$ & P-KN2 & $\begin{array}{c}0.260 \times 0.147 \\
(0.011 \times 0.009)\end{array}$ & $\begin{array}{c}0.138 \\
(0.001)\end{array}$ \\
\hline KN3 & \multicolumn{2}{|c|}{17} & $\begin{array}{l}\text { interlock } \\
\text { stitch }\end{array}$ & $13 \times 16$ & cotton $100 \%$ & $\mathrm{P}-\mathrm{KN} 3$ & $\begin{array}{c}0.051 \times 0.011 \\
(0.002 \times 0.003)\end{array}$ & $\begin{array}{c}0.103 \\
(0.001)\end{array}$ \\
\hline KN4 & \multicolumn{2}{|c|}{$23.5 / 20.5$} & milano rib & $14 \times 12$ & poly $85 \% /$ cotton $15 \%$ & P-KN4 & $\begin{array}{c}0.248 \times 0.146 \\
(0.018 \times 0.009)\end{array}$ & $\begin{array}{c}0.107 \\
(0.003)\end{array}$ \\
\hline KN5 & \multicolumn{2}{|c|}{15.5} & $\begin{array}{l}\text { interlock } \\
\text { stitch }\end{array}$ & $13 \times 14$ & cotton $100 \%$ & P-KN5 & $\begin{array}{c}0.108 \times 0.020 \\
(0.009 \times 0.004)\end{array}$ & $\begin{array}{c}0.102 \\
(0.003)\end{array}$ \\
\hline KN6 & \multicolumn{2}{|c|}{$20 / 22.5$} & milano rib & $14 \times 12$ & poly $85 \% /$ cotton $15 \%$ & P-KN6 & $\begin{array}{c}0.232 \times 0.174 \\
(0.007 \times 0.004)\end{array}$ & $\begin{array}{c}0.118 \\
(0.004)\end{array}$ \\
\hline
\end{tabular}

Table 2 Specifications of adhesive interlinings

\begin{tabular}{|c|c|c|c|c|c|c|c|c|}
\hline $\begin{array}{l}\text { Sample } \\
\text { name }\end{array}$ & $\begin{array}{l}\text { Density } \\
\text { (/cm) }\end{array}$ & $\begin{array}{l}\text { Adhesive dot } \\
\text { number }(/ \mathrm{cm}) \\
(\text { warp } \times \text { weft })\end{array}$ & $\begin{array}{l}\text { Adhesive } \\
\text { dot size } \\
(\mathbf{m m})\end{array}$ & $\begin{array}{c}\text { Mass per } \\
\text { unit area } \\
\left(\mathrm{g} / \mathrm{m}^{2}\right)\end{array}$ & $\begin{array}{c}\text { Adhesive } \\
\text { mass without } \\
\text { fabric } \\
\left(\mathbf{g} / \mathbf{m}^{2}\right)\end{array}$ & $\begin{array}{c}\text { Pressed } \\
\text { adhesive } \\
\text { interlining } \\
\text { name }\end{array}$ & $\begin{array}{c}\text { Bending rigidity } \\
\text { of pressed adhesive } \\
\text { interlining }\left(\mathrm{cN} \cdot \mathrm{cm}^{2} / \mathrm{cm}\right) \\
(\text { warp } \times \text { weft }) \\
\text { (Standard deviation) }\end{array}$ & $\begin{array}{c}\text { Thickness of } \\
\text { pressed adhesive } \\
\text { interlining(cm) } \\
\text { (Standard } \\
\text { deviation) }\end{array}$ \\
\hline CE1 & $38 \times 22$ & $10 \times 10$ & 0.17 & 36.2 & 8.6 & P-CE-1 & $\begin{array}{c}0.0058 \times 0.0051 \\
(0.0015 \times 0.0016)\end{array}$ & $\begin{array}{c}0.027 \\
(0.001)\end{array}$ \\
\hline CE2 & $38 \times 23$ & $10 \times 10$ & 0.17 & 35.6 & 8.0 & P-CE-2 & $\begin{array}{c}0.0058 \times 0.0030 \\
(0.0016 \times 0.0010)\end{array}$ & $\begin{array}{c}0.025 \\
(0.001)\end{array}$ \\
\hline CE3 & $38 \times 25$ & $10 \times 10$ & 0.17 & 36.5 & 8.3 & P-CE-3 & $\begin{array}{c}0.0060 \times 0.0035 \\
(0.0005 \times 0.0009)\end{array}$ & $\begin{array}{c}0.024 \\
(0.001)\end{array}$ \\
\hline CE4 & $37 \times 26$ & $10 \times 10$ & 0.17 & 36.5 & 8.1 & P-CE-4 & $\begin{array}{c}0.0070 \times 0.0039 \\
(0.0005 \times 0.0005)\end{array}$ & $\begin{array}{c}0.024 \\
(0.0004)\end{array}$ \\
\hline CE5 & $37 \times 26$ & $10 \times 10$ & 0.17 & 35.7 & 7.7 & P-CE-5 & $\begin{array}{c}0.0085 \times 0.0039 \\
(0.0033 \times 0.0013)\end{array}$ & $\begin{array}{c}0.023 \\
(0.001)\end{array}$ \\
\hline DP1 & $39 \times 24$ & $9 \times 9$ & 0.25 & 38.5 & 8.7 & P-DP-1 & $\begin{array}{c}0.0064 \times 0.0024 \\
(0.0009 \times 0.0010)\end{array}$ & $\begin{array}{c}0.024 \\
(0.007)\end{array}$ \\
\hline DP2 & $39 \times 24$ & $10 \times 10$ & 0.23 & 39.9 & 10.0 & P-DP-2 & $\begin{array}{c}0.0059 \times 0.0020 \\
(0.0011 \times 0.0013)\end{array}$ & $\begin{array}{c}0.024 \\
(0.006)\end{array}$ \\
\hline DP3 & $39 \times 24$ & $10 \times 10$ & 0.30 & 41.8 & 11.6 & P-DP-3 & $\begin{array}{c}0.0074 \times 0.0033 \\
(0.0007 \times 0.0009)\end{array}$ & $\begin{array}{c}0.025 \\
(0.007)\end{array}$ \\
\hline DP4 & $39 \times 24$ & $11 \times 11$ & 0.20 & 37.5 & 8.7 & P-DP-4 & $\begin{array}{c}0.0059 \times 0.0027 \\
(0.0008 \times 0.0008)\end{array}$ & $\begin{array}{c}0.024 \\
(0.007)\end{array}$ \\
\hline DP5 & $39 \times 24$ & $12 \times 12$ & 0.10 & 39.3 & 10.1 & P-DP-5 & $\begin{array}{c}0.0062 \times 0.0013 \\
(0.0008 \times 0.0017)\end{array}$ & $\begin{array}{c}0.025 \\
(0.007)\end{array}$ \\
\hline
\end{tabular}

Table 3 Combinations of face fabric and adhesive interlining

\begin{tabular}{|c|c|c|c|c|c|c|}
\hline $\begin{array}{l}\text { Face fabric } \\
\text { Adhesive interlining }\end{array}$ & KN1 & KN2 & KN3 & KN4 & KN5 & KN6 \\
\hline CE1 & KN1-CE1 & KN2-CE1 & KN3-CE1 & KN4-CE1 & KN5-CE1 & KN6-CE1 \\
\hline CE2 & KN1-CE2 & $\mathrm{KN} 2-\mathrm{CE} 2$ & KN3-CE2 & KN4-CE2 & KN5-CE2 & KN6-CE2 \\
\hline CE3 & KN1-CE3 & $\mathrm{KN} 2-\mathrm{CE} 3$ & $\mathrm{KN} 3-\mathrm{CE} 3$ & KN4-CE3 & KN5-CE3 & KN6-CE3 \\
\hline CE4 & KN1-CE4 & $\mathrm{KN} 2-\mathrm{CE} 4$ & $\mathrm{KN} 3-\mathrm{CE} 4$ & KN4-CE4 & KN5-CE4 & KN6-CE4 \\
\hline CE5 & KN1-CE5 & KN2-CE5 & KN3-CE5 & KN4-CE5 & KN5-CE5 & KN6-CE5 \\
\hline DP1 & KN1-DP1 & KN2-DP1 & KN3-DP1 & KN4-DP1 & KN5-DP1 & KN6-DP1 \\
\hline DP2 & KN1-DP2 & KN2-DP2 & KN3-DP2 & KN4-DP2 & KN5-DP2 & KN6-DP2 \\
\hline DP3 & KN1-DP3 & KN2-DP3 & KN3-DP3 & KN4-DP3 & KN5-DP3 & KN6-DP3 \\
\hline DP4 & KN1-DP4 & KN2-DP4 & KN3-DP4 & KN4-DP4 & KN5-DP4 & KN6-DP4 \\
\hline DP5 & KN1-DP5 & KN2-DP5 & KN3-DP5 & KN4-DP5 & KN5-DP5 & KN6-DP5 \\
\hline
\end{tabular}

\section{Results and discussions}

The bending rigidities of knitted fabric before and after pressing were shown in Figure 2. The bending rigidities of most knitted fabrics decreased after pressing both wale and course direction about $12 \%$. The thicknesses of 
knitted fabrics before and after pressing are shown in Figure 3. After pressing, the thicknesses of most samples, except $\mathrm{KN} 4$, become thinner about $16 \%$. Therefore, it was found that the bending rigidity and thickness of knitted fabrics changed after pressing from these results. The change rates in thickness and bending rigidity were about $6 \%$ and $3 \%$ for woven fabrics [1]. The differences of bending rigidity and thickness for knitted fabrics between before pressing and after pressing were larger than ones of woven fabrics. It is due to the structures of knitted fabric, which have larger spaces between yarns than those of woven fabric.

\section{Method 1}

As assuming the components as elastic continua, conventional laminate theory was used in Method 1. The bending rigidities of laminated fabrics were predicted using Method 1 with the obtained values of pressed samples. The comparison of the predicted bending rigidities and experimental ones are shwon in Figure 4. The mean absolute percentage errors (MAPEs) between calculated and experimental bending rigidities are shown in Table 5. In the results of experimental bending rigidities, bending rigidities of some samples were over $0.6 \mathrm{cN} \cdot \mathrm{cm}^{2} / \mathrm{cm}$ and ones of some samples were under $0.6 \mathrm{cN} \cdot \mathrm{cm}^{2} / \mathrm{cm}$. The samples of bending rigidities over $0.6 \mathrm{cN} \cdot \mathrm{cm}^{2} / \mathrm{cm}$ are all laminated knitted fabric with milano rib samples (KN2, 4 and 6). They have relatively large flexural rigidities by themselves as shown in Figure 2 . The predicted bending rigidities of laminated knitted fabric with milano rib samples were much smaller than the experimental ones. The predicted bending rigidities of laminated knitted fabric with KN1, 3 and 5 were closer to the experimental ones than the laminated knitted fabric with milano rib samples, KN 2, 4 and 6. However, even though the predicted results of laminated knitted fabric with KN2, 4 and 6 (MAPE 15.0\%) showed closer agreements with experimental ones than those of the laminated knitted fabric with milano rib samples (MAPE 31.6\%), it is still resulted in large prediction errors (MAPE 19.1\%). The reasons of disagreement in laminated knitted fabric with milano rib samples will be the difference between elastic modulus in bending, and tensile and in-plane compressive moduli, or the placement of neutral axes in the knitted fabrics. This will be discussed in the parts of Method 2 and 3. Due to the large prediction errors, it was found that Method 1 was not suitable for predicting bending rigidities of laminated knitted fabrics.

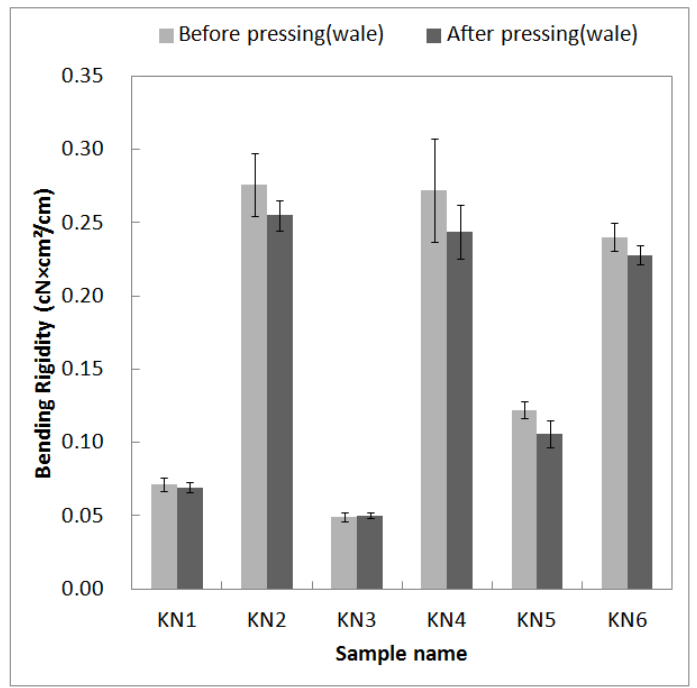

(a)

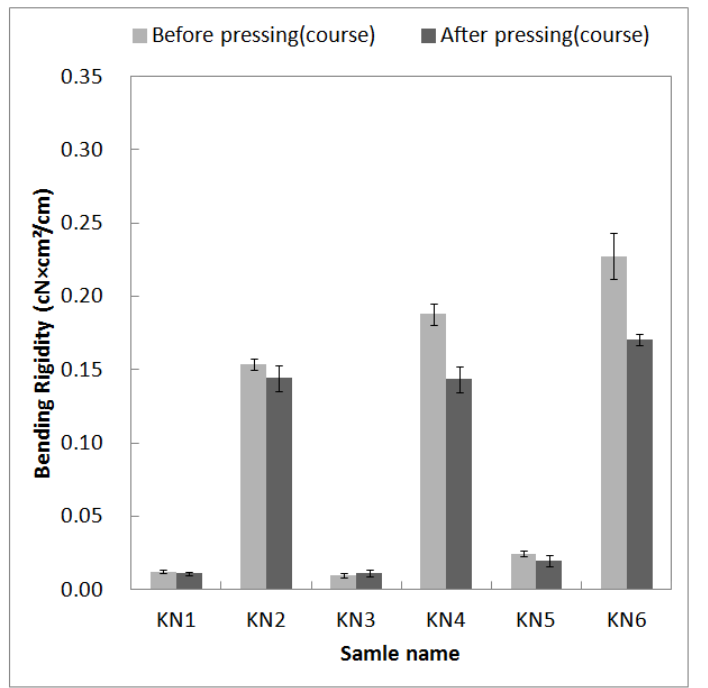

(b)

Figure 2 Bending rigidities of knitted fabrics; (a) wale direction, (b) course direction.

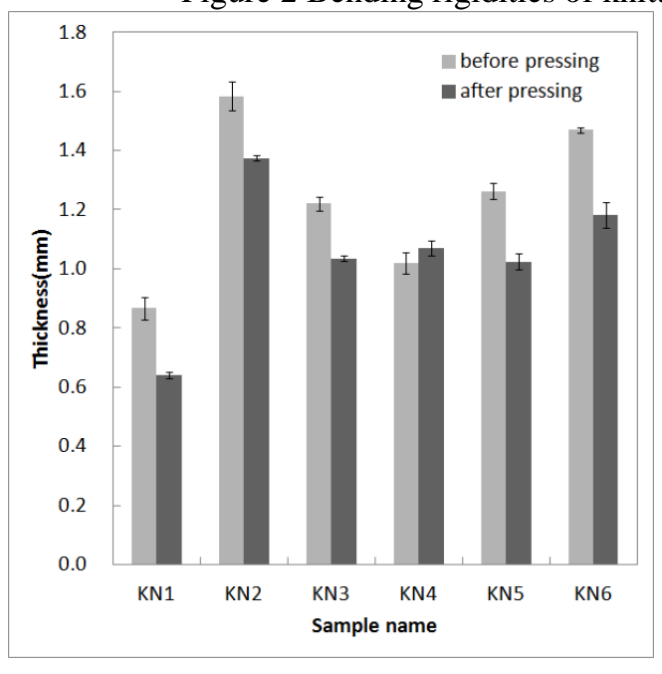

Figure 3 Thicknesses of knitted fabrics before and after pressing. 


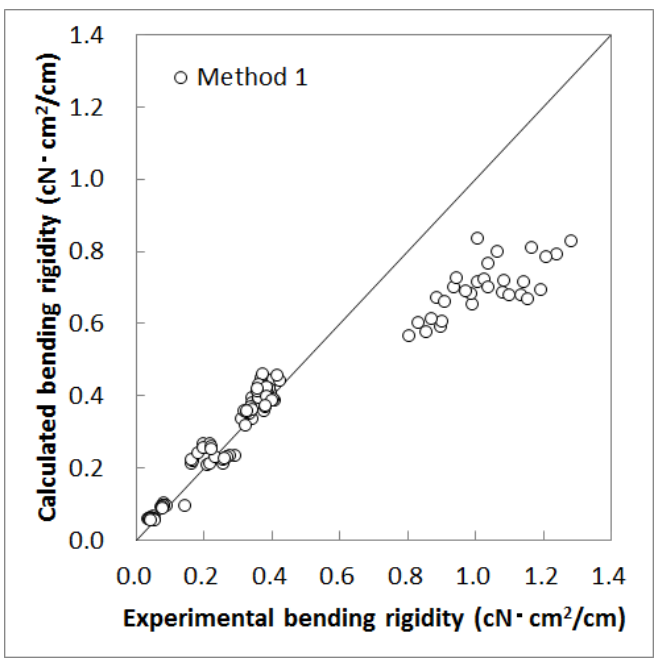

Figure 4 Calculated and experimental bending rigidities of laminated knitted fabrics using Method 1 .

\section{Method 2}

In Method 2, aparent in-plane compressive modulus and tensile modulus were taken into account based on the Method 1. In addition to the bending rigidity and thickness, apparent in-plane compressive modulus of interlining $T_{1}$ and tensile modulus of face fabric $T_{2}$ are necessary to calculate the bending rigidities of laminated fabrics in Method 2. $T_{2}$ were obtained from the tensile properties of pressed knitted fabrics as shown in Table 4. In Method 2, if the neutral axes in bending of the components are in the centroid, the $T_{1}$ can be obtained using Equation (3). However, the placements of the neutral axes for knitted fabrics are uncertain. Thus, the placements of knitted fabrics were investigated. The obtained $T_{1}$ values using Equation (3) with the bending rigidities and thicknesses of the knitted fabrics were compared with the obtained $T_{1}$ values with those of $\mathrm{N} 1$ and $\mathrm{N} 2$. The comparison of the average of $T_{1}$ values with knitted fabrics and twill fabrics by Equation (3) are shown in Figure 5. If the neutral axes in bending of knitted fabrics are in the centroid, the $T_{1}$ values will be the same as the $T_{1}$ values from the tests with twill fabrics. However, the averages were significantly different when compared to those from twill fabrics. The variations of $T_{1}$ values for the knitted fabrics were also large. Therefore, it was found that the neutral axes in bending of the knitted fabric samples are not in the centroid. The position of the neutral axes in bending of the knitted fabrics will be discussed as the part of Method 3. Therefore, $T_{1}$ values from twill fabrics were used in Method 2. With the resulting bending rigidities, thicknesses, $T_{1}$ and $T_{2}$ values of pressed samples, the bending rigidities of laminated fabrics were calculated as shown in Figure 6. The MAPEs between calculated and experimental bending rigidities are shown in Table 5. As shown in Figure 6 and its MAPEs, the calculated bending rigidities of laminated knitted fabrics did not correlate with the experimental ones.

The reason of the disagreements between predicted and experimental bending rigidities by Method 2 is due to the position of the neutral axes in bending of face fabrics. As mentioned previously, the neutral axes in bending of knitted fabrics were not in the centroids. When the neutral axes in bending of components are not in the centroid, it is necessary to consider $Y_{2}$. Therefore, it was found that Method 2 is not suitable for predicting bending rigidities of laminated knitted fabrics.

Table $4 T_{2}$ of pressed face fabrics

\begin{tabular}{cc}
\hline Sample name & $\boldsymbol{T}_{\mathbf{2}}(\mathbf{c N} / \mathbf{c m})$ \\
\hline P-N1(warp) & 14.4 \\
P-N1(weft) & 28.9 \\
P-N2(warp) & 22.8 \\
P-N2(weft) & 4.2 \\
P-KN1(warp) & 368.1 \\
P-KN1(weft) & 107.3 \\
P-KN2(warp) & 544.0 \\
P-KN2(weft) & 152.6 \\
P-KN3(warp) & 274.6 \\
P-KN3(weft) & 48.4 \\
P-KN4(warp) & 1130.7 \\
P-KN4(weft) & 239.5 \\
P-KN5(warp) & 486.7 \\
P-KN5(weft) & 85.9 \\
P-KN6(warp) & 545.0 \\
P-KN6(weft) & 226.9 \\
\hline
\end{tabular}

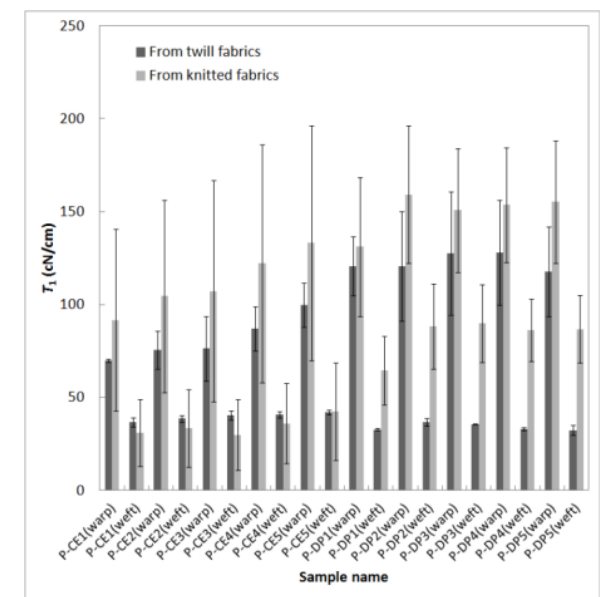

Figure 5 Comparison of averages $T_{1}$ of interlinings from tests with twill fabrics and knitted fabrics. 


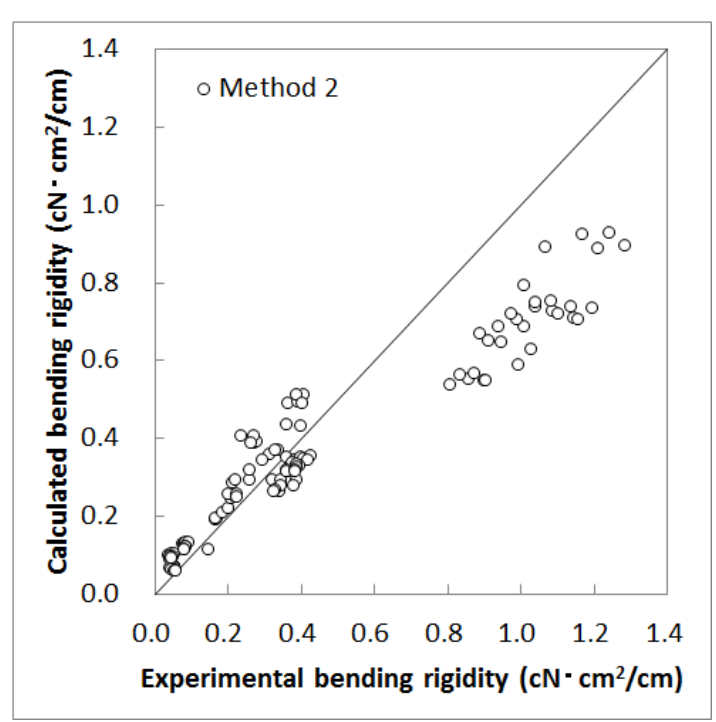

Figure 6 Calculated and experimental bending rigidities of laminated knitted fabrics using Method 2

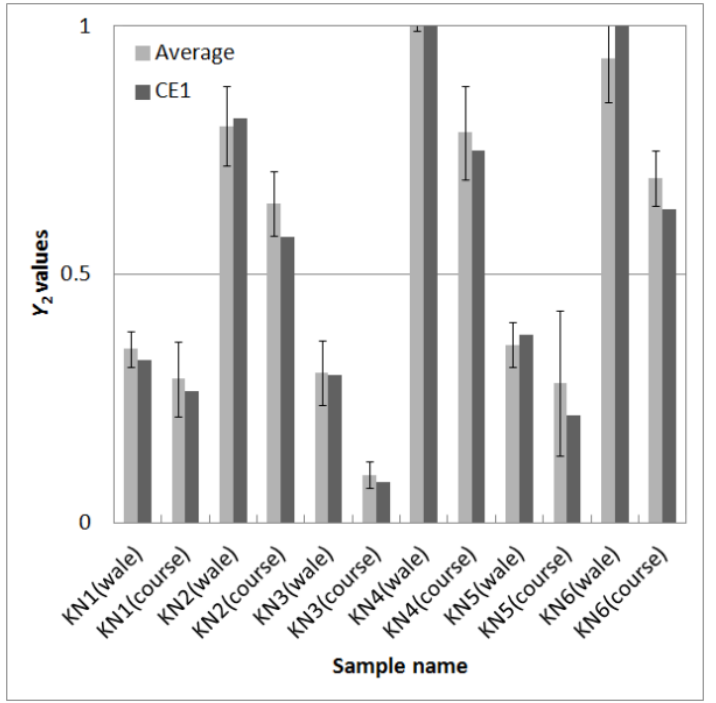

Figure 7 Average $Y_{2}$ of knitted fabrics and $Y_{2}$ from composites with CE1 interlining.

\section{Method 3}

The relative position of neutral axis in bending was taken into account for Method 3 in addition to Method 2 . $Y_{2}$ is necessary to predict bending rigidity of laminated knitted fabric using Method 3. The average of $Y_{2}$ for face fabrics were obtained from composites with different adhesive interlinings as shown in Figure 7. When $Y_{2}$ is close to 0, it means that the neutral axis in bending is close to the bottom of a face fabric. On the other hand, when $Y_{2}$ is close to 1 , it means that the neutral axis in bending is close to the top of a face fabric. When $Y_{2}$ is close to 0.5 , it means that the neutral axis in bending is close to the centroid. As shown in Figure 7, it was found that $Y_{2}$ of the most knitted fabrics do not lie in the centroid.

$Y_{2}$ obtained using the data of laminated fabric with CE1 interlining (Figure 7) were arbitrarily selected for calculating bending rigidities of laminated knitted fabric. The calculated and experimental bending rigidities of laminated knitted fabrics by Method 3 are shown in Figure 8 with the results by other methods. The MAPEs between calculated and experimental bending rigidity are shown in Table 5. The predicted bending rigidities showed good agreements with experimental ones. Especially, the calculated bending rigidities of laminated knitted fabric with milano rib samples using Method 3 showed good agreements with the experimental ones. These results showed that $Y_{2}$ for knitted fabric are not in the centroid and must be taken into account to calculate the bending rigidity of laminated fabric with knitted fabrics.

\section{Comparison of three methods}

The comparisons of calculated and experimental bending rigidities of laminated knitted fabrics using three methods are shown in Figure 9. Among the predicted bending rigidities using three methods, the results by Method 3 showed the closest correlation to the experimental ones as shown in its MAPE, 6.9\%.

For all samples, Method 2 showed the largest MAPE, over 35\%. Method 1 also showed relatively large MAPE, over 19\%. As mentioned above, especially for the milano rib samples, results by Method 1 and 2 showed large MAPEs. It is due to the tensile and in-plane compressive moduli of knitted fabric are significantly different so it is necessary to be considered. According to these results, it became clear that Method 1 and 2 are hard to be used to predict bending rigidity of laminated knitted fabrics.

In the case of woven fabric, the calculated results of some face fabric by Method 2 showed good agreements with experimental ones [2]. For the samples with large prediction errors by Method 2, the calculated results by Method 3 showed better agreements with the experimental results than ones by Method 2 [3]. However, in the case of knitted fabrics, the calculated results by Method 2 still showed large prediction errors for all samples in the results of this study. These results showed that the knitted fabrics are more affected by the position of the neutral axis so the results by Method 2 showed large prediction errors. Accordingly, the position of neutral axis for knitted fabric must be considered to calculate the bending rigidity of laminated fabric.

In conclusion, it was found that Method 3 is the most suitable method to precisely calculate bending rigidities of laminated fabrics with knitted fabrics. 


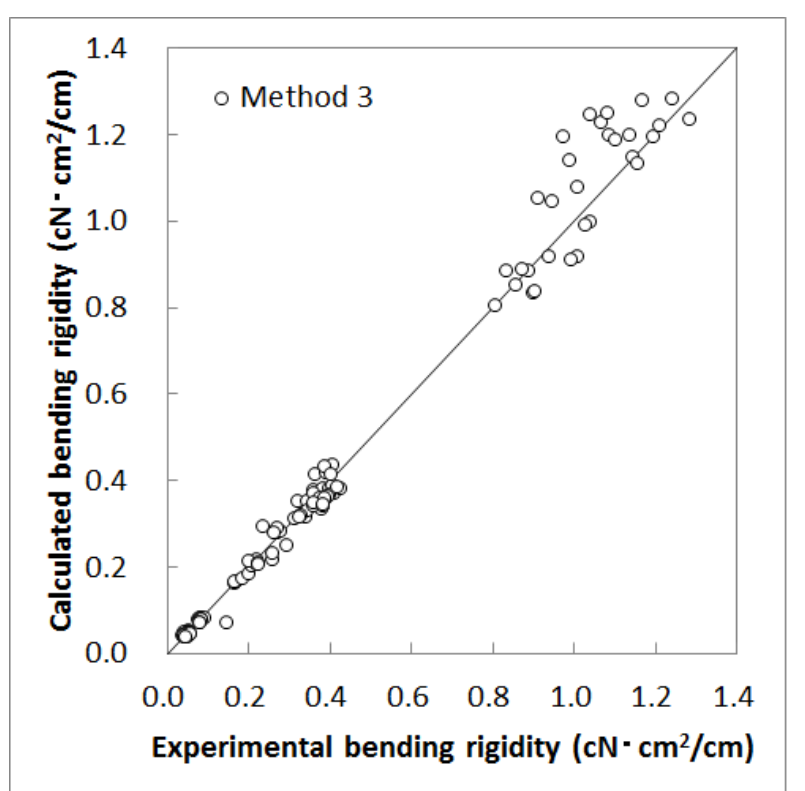

Figure 8 Calculated and experimental bending rigidities of laminated knitted fabrics using Method 3

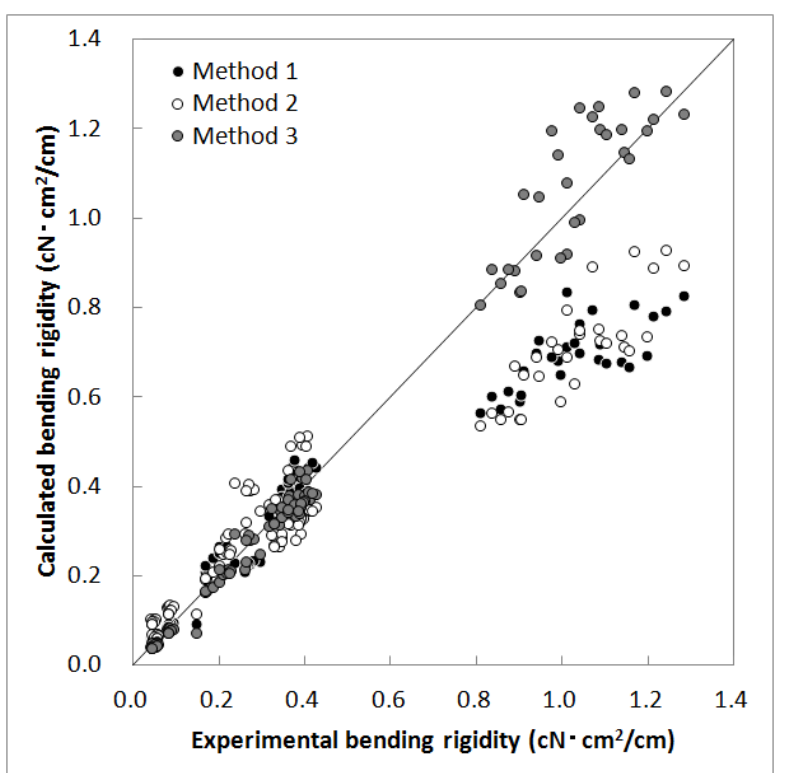

Figure 9 Calculated and experimental bending rigidities of laminated knitted fabrics using three methods.

Table 5 Mean absolute percentage errors (MAPEs) between calculated and experimental bending rigidity

\begin{tabular}{cccc}
\hline Method & Method 1 & Method 2 & Method 3 \\
\hline Sample condition & 19.1 & 35.3 & 6.9 \\
All laminated knitted fabrics & 31.6 & 31.0 & 7.2 \\
laminated knitted fabric with KN2, 4 and 6 & 15.0 & 36.7 & 6.8 \\
\hline
\end{tabular}

\section{Conclusion}

Bending rigidities of laminated knitted fabrics with adhesive interlinings were calculated using three prediction methods with mechanical properties of components such as $h_{1}, h_{2}, B_{1}, B_{2}, T_{1}, T_{2}$ and $Y_{2}$. The predicted bending rigidity of laminated knitted fabrics by both Method 1 and 2 showed large prediction errors. The predicted results using Method 3 in consideration of $Y_{2}$ showed the strong correlation with the experimental ones among the predicted ones by the other methods.

Therefore, it was found that the disagreement in the results using Method 1 and 2 was due to the position of the neutral axis. With these results, it became clear that $Y_{2}$ of a knitted fabric must be taken into account for predicting the bending rigidity of laminated knitted fabric more precisely. A suitable adhesive interlining for a knitted fabric can be selected using Method 3. Until now, the selection of adhesive interlining was carried out based on experiments and previous data. If the data concerning adhesive interlinings and face fabrics has been compiled once, the prediction of the performance of laminated fabrics made of different combination will be possible. Designers and manufacturers will be able to reduce the cost and time for selecting a suitable adhesive interlining.

\section{References}

1. Kim KO, Inui S and Takatera M. Verification of Prediction for Bending Rigidity of Woven Fabric Laminated with Interlining by Adhesive Bonding. Textile Research Journal 2011; 81(6): 598-607.

2. Kim KO, Inui S, and Takatera M. Prediction of bending rigidity for laminated fabric with adhesive interlining by a laminate model considering tensile and in-plane compressive moduli. Textile Research Journal 2012; 82(4): 385-399.

3. Kim KO, Inui S, and Takatera M. Textile Research Journal, 2012 in press

4. Viki L. Gibson and Postle R. An Analysis of the Bending and Shear Properties of Woven, Double-Knitted, and Warp-Knitted Outerwear Fabrics, Textile Research Journal 1978; 48: 14-27.

5. D. ALIMAA, T. M1 ATSUO, M. NAKAJIMA, AND M. TAKAHASHI. Effects of Yarn Bending and Fabric Structure on the Bending properties of Plain and Rib Knitted Fabrics, Textile Research Journal 2000; 70 : 783

6. Dawes V H and Owen J D. The handle and bending behavior of fabric laminates J.Text. Inst. 1972; 63: T446-474.

7. Shishoo R, Klevermar P H, Cednas M, and Olofsson B. Multilayer Textile Structure. Textile Research Journal 1971; 41:669-679. 
8. Kawabata S. The standardization and analysis of hand evaluation,2nd ed. Osaka, Japan: The Textile Machinery Society of Japan, 1980 